\title{
POMICS: A Simulation Disease Model for Timing Fungicide Applications in Management of Powdery Mildew of Cucurbits
}

\author{
Z. Sapak,† M. U. Salam, E. J. Minchinton, G. P. V. MacManus, D. C. Joyce, and V. J. Galea
}

First author: Faculty of Plantation and Agrotechnology, MARA University of Technology, Shah Alam, Selangor, 40450, Malaysia; first, fifth, and sixth authors: School of Agriculture and Food Sciences, The University of Queensland, Gatton 4343, QLD, Australia; second author: Food and Agriculture Organization of the United Nations (FAO), FAO Representation in Bangladesh, House 37; Road 08; Dhanmondi R/A, Dhaka-1205, Bangladesh; third author: Department of Economic Development, Jobs, Transport and Resources, 475 Mickleham Road, Attwood, VIC 3047, Australia; fourth author: Horticulture and Forestry Science, Agri-Science Queensland, Department of Employment, Economic Development and Innovation, PO Box 15, Ayr, QLD 4807, Australia; and fifth author: Department of Agriculture and Fisheries, Level 2C West, Ecosciences Precinct, Box 267, Brisbane, QLD 4001, Australia.

Accepted for publication 16 May 2017.

\begin{abstract}
A weather-based simulation model, called Powdery Mildew of Cucurbits Simulation (POMICS), was constructed to predict fungicide application scheduling to manage powdery mildew of cucurbits. The model was developed on the principle that conditions favorable for Podosphaera xanthii, a causal pathogen of this crop disease, generate a number of infection cycles in a single growing season. The model consists of two components that (i) simulate the disease progression of $P$. xanthii in secondary infection cycles under natural conditions and (ii) predict the disease severity with application of fungicides at any recurrent disease cycles. The underlying environmental factors associated with $P$. xanthii infection were quantified from laboratory
\end{abstract}

ABSTRACT

Powdery mildew of cucurbits caused by the obligate fungal pathogen Podosphaera xanthii (Castagne) U. Braun \& Shishkoff (syn. P. xanthii, formerly Sphaerotheca fuliginea) is a major disease causing extensive economic loss in cucurbit production worldwide, including in Australia (McGrath 2001; Pérez-García et al. 2009). The disease affects all commercially grown cucurbit species and causes premature senescence of leaves and consequent exposure of fruit to sunscald. Fruit produced from severely infected plants are often small in size, with poor taste and texture qualities.

The application of fungicides is an essential practice to control powdery mildew on cucurbits such as zucchini (Cucurbita pepo L.) in many parts of the world (Keinath 2015; McGrath and Staniszewska 1996; O'Brien et al. 1988). For example, growers in Queensland, Australia, schedule weekly alternated contact and systemic fungicide applications after initial disease symptoms are observed in crops (Dal Santo and Holding 2009). This practice ignores the fact that pathogen development is critically influenced by environmental conditions that can result in low- or high-risk disease events (Madden et al. 2007). Scheduled application of fungicides during low-risk periods and delayed application under high-risk situations can lead to unjustified applications and poor timing of applications, respectively. Such practice can also lead to problems such as fungicide resistance (BenNaim and Cohen 2015; McGrath 2001) and ecosystem disturbance because frequent use of fungicides and direct applications to soil likely affect one or more aspects of nutrient cycling and soil microbiota (Cheatham et al. 2009). There is a need for strategic and tactical disease management programs to minimize disease severity (DS) and prevent fungicide resistance from happening.

${ }^{\dagger}$ Corresponding author: Z. Sapak; E-mail: zaiton3338@salam.uitm.edu.my

(c) 2017 The American Phytopathological Society and field studies, and also gathered from literature. The performance of the POMICS model when validated with two datasets of uncontrolled natural infection was good (the mean difference between simulated and observed disease severity on a scale of 0 to 5 was 0.02 and 0.05 ). In simulations, POMICS was able to predict high- and low-risk disease alerts. Furthermore, the predicted disease severity was responsive to the number of fungicide applications. Such responsiveness indicates that the model has the potential to be used as a tool to guide the scheduling of judicious fungicide applications.

Additional keywords: temperature, vapor pressure deficit.
Weather variables such as temperature, relative humidity $(\mathrm{RH})$, and vapor pressure deficit (VPD) can greatly affect powdery mildew incidence and severity on cucurbits. A study by Reuveni and Rotem (1974) reported that $P$. xanthii displayed optimal conidial germination (GER) and infection on squash leaves at temperatures of 20 and $25^{\circ} \mathrm{C}$ and $\mathrm{RH}$ of 50 to $55 \%$. Low and high temperatures on the order of $\leq 15^{\circ} \mathrm{C}$ and $\geq 31^{\circ} \mathrm{C}$, respectively, prolong the incubation and latent period (LP) of $P$. xanthii and result in low disease inoculum levels. The LP is the interval between inoculation and production of a new conidial generation, and the length of the LP is an important factor affecting inoculum production (Vanderplank 1982; van Maanen and $\mathrm{Xu}$ 2003). It determines the number of potential infection cycles (ICY) that can be completed by a pathogen within a growing season (de Vallavieille-Pope et al. 2000). The shorter the LP, the higher the number of ICY the pathogen can complete per growing season, resulting in high DS in cucurbits. Weather patterns can vary between and within seasons, influencing the disease and its management. A reliable weather-based disease warning system based on understanding the interrelationship of the pathogen, host, and environment could offer an improved management approach for powdery mildew in cucurbits. Ideally, this system would be used to warn growers when crop conditions are favorable or unfavorable for disease development, assist growers in making rational crop protection decisions, and potentially reduce the number of fungicide applications and minimize development of fungicide resistance. Weather-driven simulation models which use microclimate data to predict disease development have been created as a first step in developing a disease warning system for powdery mildews of crops such as wheat (Cao et al. 2015; Rossi and Giosué 2003), grape (Arafat 2015; Caffi et al. 2012; Moyer et al. 2016), and apple (Xu 1999). To the authors' knowledge, no such model has been reported for powdery mildew on cucurbits.

This article presents a weather-driven simulation model for powdery mildew on zucchini as the first step in developing a 
warning system to manage the disease in cucurbit crops. Here, we have described the development of the model, calibration of its parameters, its validation, and application in fungicide scheduling.

\section{MATERIALS AND METHODS}

The Powdery Mildew of Cucurbits Simulation model and its development. The Powdery Mildew of Cucurbits Simulation (POMICS) model has two components: (i) a simulation of the natural recurrent progression in $P$. xanthii secondary ICY and final DS on cucurbit (i.e., zucchini) status within a single growing season and (ii) prediction of DS with application of fungicides within recurrent disease cycles. The relational diagram of the model accounting for the relationships between the processes involved in the ICY and the final status of the DS in zucchini is presented in Figure 1. It is based on generally accepted understanding of the cucurbit powdery mildew lifecycle (McGrath 1994, Pérez-García et al. 2009). In the simulation model, the GER process commences when the symptom of white powdery patches is first observed in the crop. POMICS considers the initial status of powdery mildew, termed initial disease severity (IDS), as an initialization parameter (input) in the model. The value of IDS is based on a 0-to-5 DS scale (MacManus and Akem 2008), described later. The model assumes that IDS occurs as a result of natural primary infection initiated by perennating mycelia or conidia from infected alternative hosts from families such as the Asteraceae, Lamiaceae, Scrophulariaceae, Solanaceae, and Verbenaceae (Cunnington et al. 2004; McGrath 2001;
Pérez-García et al. 2009) and that IDS represents a large number of potentially infective conidia. The potentially infective conidia have the capability to germinate and infect healthy growing zucchini leaves under favorable environmental conditions. The model's simulation begins with the assumption that conidia (IDS) are mature and viable for germination to initiate infection. GER is controlled by four environmental parameters. Those are thresholds of (i) low temperature (low_ $\mathrm{T}_{\text {threshold }}$ ), (ii) high temperature (high_ $\mathrm{T}_{\text {threshold }}$ ), (iii) small VPD (small_VPD threshold), and (iv) large VPD (large_VPD threshold). After IDS is recognized in the field, each subsequent hour is classified as either favorable for the inoculation process $(=1)$ or unfavorable $(=0)$, according to equation 1 . The accumulation of temperatures and VPD in hour will start when conidia (IDS) are observed in the field and both parameters are favorable for the inoculation process.

$$
\begin{array}{r}
\text { GER = } 1 \text {, if cumulative temperature in hour } t \geq \text { low_T }_{\text {threshold }} \\
\text { and } \leq \text { high_ } \mathrm{T}_{\text {threshold }} \text { and cumulative VPD in hour } \\
t \geq \text { small_VPD } \mathrm{V}_{\text {threshold }} \text { and } \leq \text { large_VPD }
\end{array}
$$

$$
\begin{aligned}
\text { GER }= & 0, \text { if cumulative temperature in hour } t \leq \text { low_ } T_{\text {threshold }} \\
& \text { and } \geq \text { high_ } \mathrm{T}_{\text {threshold }} \text { and cumulative VPD in hour } \\
& t \leq \text { small_VPD } \text { threshold }_{\text {and }} \geq \text { large_VPD }
\end{aligned}
$$

Once GER is initiated, the model progresses to simulate the LP (i.e., time period from infection to sporulation) that would influence the length of time (hours) of the ICY which determines the number

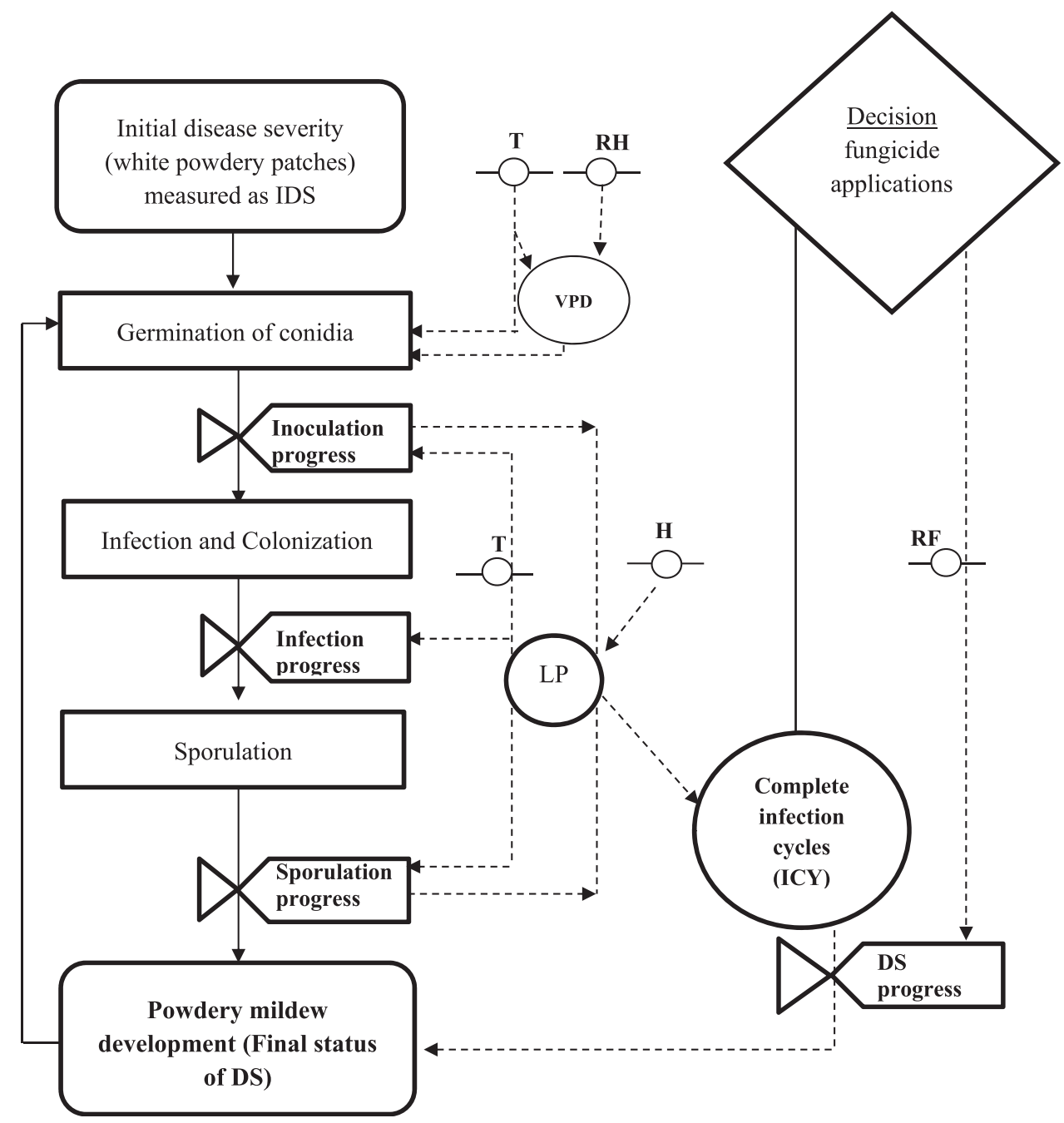

Fig. 1. Relational diagram of the POMICS model simulating secondary infection cycles of powdery mildew in zucchini, where $\mathrm{DS}=$ disease severity, $\mathrm{H}=$ required hours, $\mathrm{IDS}=$ initial disease severity, $\mathrm{LP}=$ latent period, $\mathrm{RH}=$ relative humidity, $\mathrm{RF}=$ reduction factor, $\mathrm{T}=$ temperature, and $\mathrm{VPD}=$ vapor pressure deficit. 
of ICY that can be completed during a growing season (van Maanen and $\mathrm{Xu}$ 2003; Zadoks 1972). LP is influenced by temperature and quantified by two parameters: low temperature (low_T threshold) and high temperature (high_ $\mathrm{T}_{\text {threshold }}$ ). Each hour is classified as either favorable $(\mathrm{LP}=1)$ or unfavorable $(\mathrm{LP}=0)$, according to equation 2. $\mathrm{LP}$ requires ICY hours of cumulative favorable temperature, which is a parameter of the model. Once LP has been achieved, POMICS assumes that an ICY period (e.g., ICY-1) is completed and a new ICY (e.g., ICY-2) will commence. The accumulation of temperatures in an hour will start on the completion of one cycle (ICY) and temperatures are favorable for the inoculation process.

$$
\begin{aligned}
\mathrm{LP}= & 1, \text { if cumulative temperature in hour } \mathrm{t} \geq \text { low_ } \mathrm{T}_{\text {threshold }} \\
& \text { and } \leq \text { high_ } \mathrm{T}_{\text {threshold }} \\
\mathrm{LP}= & 0 \text {, if cumulative temperature in hour } t \leq \text { low_ } \mathrm{T}_{\text {threshold }} \\
& \text { and } \geq \text { high_ } \mathrm{T}_{\text {threshold }}
\end{aligned}
$$

Next, POMICS simulates the final status of DS on zucchini leaves in a single growing season according to the number of ICY achieved and will contribute to the increase of crop DS. A logistic model function was used to describe the relationship between ICY and the increase in DS (equation 3):

$$
\mathrm{DS}=(D \operatorname{Smax}-D \operatorname{Smin}) /\left(1+e^{a+b x}\right)
$$

where DSmax is the maximum DS achieved (the highest DS is 5, based on a scale of 0 to 5), DSmin is the minimum DS achieved (the lowest value of DS is 0 , based on a scale of 0 to 5), $a$ and $b$ are parameters, and $x$ is the total number of complete ICY periods. The model further predicts the reduction in DS due to the application of fungicides at any recurrent ICY. The model assumes that, with the application of fungicides at a recurrent ICY, DS is reduced by a reduction factor (RF) in the following ICY. RF is a parameter that refers to the effectiveness of fungicides in reducing DS. In this model, RF is calculated according to Caffi et al. (2012) (equation 4):

$$
\operatorname{RF}(\%)=100-\left[\left(Y_{s} / Y_{u}\right) \times 100\right]
$$

where RF is the reduction factor, $Y_{s}$ is DS in the sprayed treatment (industry standard practice [INS]), and $Y_{u}$ is DS in the unsprayed treatment (CON). The model was written in Microsoft Excel 2007 worksheets.

Data for model calibration, validation, and simulation. Three field studies, summarized below, were conducted to generate data for model calibration and validation (Sapak 2012).

Field trial 1. The trial was conducted at the Queensland Department of Agriculture and Fisheries (QDAF) Research Station in Bowen, North Queensland, Australia, during spring 2008. It was carried out by MacManus and colleagues of QDAF. The initial aims of this trial were not for this study; however, relevant data were coopted for use in the POMICS model as a component of this broader national activity. 'Congo' zucchini seed (Seminis Vegetable Seeds Inc.) were sown into 96-cell seedling trays using a 3:1 ratio of peat to vermiculite and the seedlings were raised in an evaporatively cooled glasshouse for 2 weeks. Four experimental plots $1.52 \mathrm{~m}$ apart were prepared with black plastic mulch and trickle irrigation (flow rate $=$ 2 liters/min). These plots were assigned in a completely randomized block design with four treatments of sequential planting dates on 26 June and 11, 24, and 30 July because the study aimed to assess the influence of different planting times and weather variables on disease development. Each treatment consisted of four replicate raised beds, and 10 zucchini seedlings with three unfolded leaves from the glasshouse were transplanted into each bed and spaced $0.55 \mathrm{~m}$ apart. The five centermost plants were used for DS assessments. DS assessments were made weekly on leaves within the lower third of the canopy using a 0 -to- 5 scale, where $0=$ nil and $1=1$ to $5,2=6$ to $10,3=11$ to $25,4=31$ to 75 , and $5=76$ to $100 \%$ of leaf area covered with sporulating lesions (MacManus and Akem 2008). Hourly weather data of temperature and $\mathrm{RH}$ were recorded with a monitoring weather station. Standard agronomic practices for weed control, fertilization, and pest management were implemented throughout the growing season and no fungicides were applied (MacManus and Akem 2008). Environmental conditions in Bowen favored the rapid development of powdery mildew regardless of planting dates and, therefore, only DS data from one plating date were used in this study.

Field trial 2. This field trial was conducted during autumn 2011 at the QDAF Research Station, Gatton, southeast Queensland, Australia, and planted with 'Amanda' zucchini (Henderson Seed Co. Pty. Ltd). Twenty-one experimental plots were prepared with plastic mulch and trickle irrigation (2 liters $/ \mathrm{min}$ ). These plots were assigned in a completely randomized design with three treatments: (i) no fungicide applications (CON), (ii) fungicide applications according to the INS, and (iii) fungicide applications according to the University of California-Davis powdery mildew risk assessment index (RAI), as developed by Gubler et al. (1999). There were seven replicated plots per treatment and each plot consisted of four raised beds $(5.0$ by $1.5 \mathrm{~m})$, each direct seeded for 10 plants spaced $0.55 \mathrm{~m}$ apart. Four plants from the central beds were randomly selected for the DS assessments and two outer beds were used as buffers. DS assessments in this study were made as described for field trial 1. Standard agronomic practices for irrigation, weed control, insect pest management, and fertilization were applied (Napier 2009). In the early stage of plant growth, fungicides were not applied in order to allow natural primary infection of powdery mildew to occur. Weather data, consisting of hourly temperature and $\mathrm{RH}$, were recorded at crop height with a SMARTLOGGER portable monitoring weather station (Monitor Sensors Pty. Ltd.). Initial pathogen appearance on leaves was observed on 7 March during the flowering stage but was very low at $\leq 1 \%$ of leaf area covered by powdery mildew colonies. No fungicide applications were applied until 21 March. Subsequently, the systemic fungicide Azoxystrobin (Amis$\operatorname{tar} 250$ SC; Syngenta Australia) was applied at a rate of $120 \mathrm{ml}$ per 100 liters with a tractor-mounted boom application for the INS treatment, as recommended by industry practice. The RAI treatment was based on the calculated RAI (Sapak 2012). This field trial was carried out for 7 weeks, with four applications of fungicides for treatment INS and three applications for treatment RAI (Table 1).

Field trial 3. This field trial was carried out during spring 2011. The location, field procedures, and data collections were as previously described for field trial 2 . Fifteen experimental plots were prepared and assigned in a completely randomized design with three treatments and five replicates per treatment. The treatments were (i) no fungicide applications (CON), (ii) fungicide applications according to INS, and (iii) fungicide applications according to the POMICS model. In this experiment, three fungicide applications were applied for the treatment (INS) and two applications for POMICS.

Model calibration, validation, and simulation. POMICS has nine parameters (Table 2), of which IDS is an initialization parameter (considered a primary input) which needs to be measured or estimated in the field based on a 0-to-5 DS scale. Of the remaining eight parameters, Small_VPD threshold $_{\text {and Large_ }}$ VPD $_{\text {threshold }}$ were measured in the laboratory study (Sapak 2012) (Table 2, column 4). The ICY was valued according to Reuveni and Rotem (1974) and Sapak (2012). The remaining four parameters (Low_T $\mathrm{T}_{\text {threshold}}$, High_T threshold, $a$, and $b$ ) were valued through calibration. This calibration was performed using the "solver" function of Microsoft Excel 2007 as recommended by Salam et al. (2007). The solver function of Microsoft Excel 2007 is designed to define an optimal value for a formula that includes a number of parameters. The solver function was applied in this case to minimize the sum of the squared differences between the observed 
DS in the field and simulated DS values according to the model. The observed DS data used for the parameter calibration are the DS data obtained from field trial 2 for treatment CON. The value of the parameter RF was calculated using equation 4 with the same DS data set from field trial 2. The DS data observed on week 7 in the CON and INS treatments were used to calculate the RF value as follows:

$$
\begin{gathered}
\mathrm{RF}(\%)=100-\left[\left(Y_{s} / Y_{u}\right) \times 100\right] \\
\mathrm{RF}(\%)=100-[(0.3 / 3.5) \times 100] \\
\mathrm{RF}=91 \approx 90 \%
\end{gathered}
$$

where $Y_{s}$ is minimum DS from the applied treatment (INS) and $Y_{u}$ is maximum DS from the no fungicide treatment (CON). The parameter RF was included in POMICS to simulate DS after fungicides were applied to the crop. The model assumes that the application of fungicides at a recurrent ICY can reduce DS by $90 \%$ in the next ICY. Therefore, the POMICS model suggests the fungicide applications to control powdery mildew of zucchini according to the number of complete ICY.

In order to judge the performance of the prediction, the model was validated with two independent datasets, Validation of POMICS was performed first with the DS data from field trial 1 and second with the DS data from field trial 3 using the CON treatment. In addition to simulating the DS, POMICS also predicts the reduction in DS due to the application of fungicides at any recurrent ICY, as mentioned earlier. The effectiveness of the POMICS model approach in assisting fungicide applications was tested with four independent datasets of observed DS. Of these, the first two datasets were from field trial 2. Here, the INS treatment with four fungicide applications and the RAI treatment with three fungicide applications for controlling powdery mildew on zucchini were used to compare with the POMICS simulation. Another two datasets were used from field trial 3 with respect to the INS treatment, where three fungicide applications were applied, and the POMICS treatment, where two were applied.

Statistical analysis used in model calibration, validation, and simulation. The performance of the model was evaluated statistically by using three techniques: (i) confidence interval of DS observation, (ii) concordance correlation coefficient (CCC) of simulation versus observation, and (iii) deviation of simulation minus observation. The confidence interval was calculated for each mean value of DS observation at the $95 \%$ confidence level (Willmott et al. 1985). The purpose of this analysis was to explore whether the range of the true mean value of an observation overlapped with the corresponding simulation at the confidence

TABLE 1. Changes in disease severity levels (0 to 5) on both zucchini leaf surfaces in response to fungicide treatment applied according to the risk assessment index (RAI) and standard industry practice (INS) recommendations during 7 weeks of observation

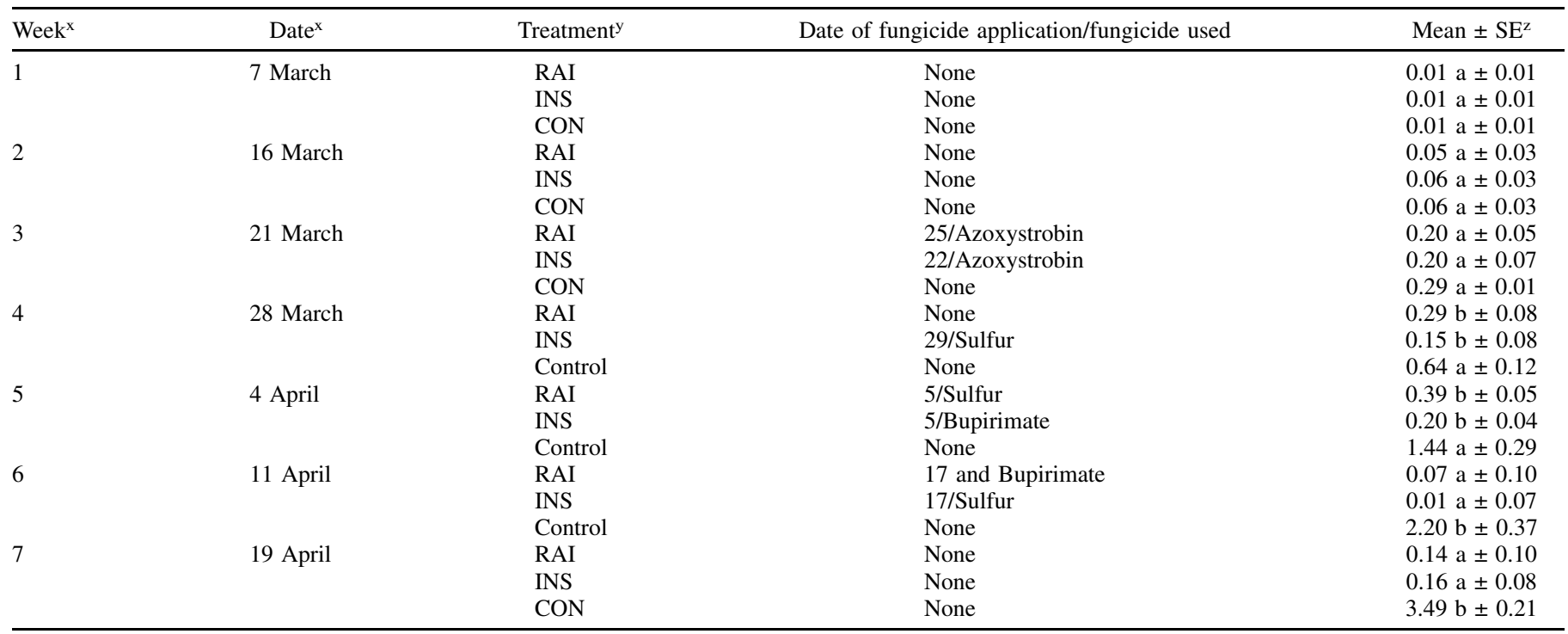

$\mathrm{x}$ Week and date of disease severity (DS) observations.

y RAI is a treatment of fungicide application according to the risk assessment index developed by Gubler et al. (1999), with modifications. INS is a treatment of fungicide application according to the industry standard practice. $\mathrm{CON}$ indicates no fungicide treatment.

z DS scale of 0 to 5 . Means \pm standard error (SE) within the column indicated with the same letter are not significantly different according to the $t$ test at a

\begin{tabular}{|c|c|c|c|}
\hline Parameter & Definition & Unit & Parameter value \\
\hline IDS & Initial disease severity (DS) found in the cucurbit field, measured on the basis of a scale of 0 to 5 & Unitless & Various \\
\hline ICY & $\begin{array}{l}\text { Number of favorable hours to complete the infection cycle (ICY), consisting of } \\
\text { progress of inoculation to sporulation }\end{array}$ & $\mathrm{h}$ & 168 \\
\hline High_T threshold & Upper limit of mean hourly temperature required for conditions to be favorable for the ICY & ${ }^{\circ} \mathrm{C}$ & 30 \\
\hline Small_VPD threshold & $\begin{array}{l}\text { Lower limit of mean hourly vapor pressure deficit (VPD) required for conditions to be } \\
\text { favorable for the ICY }\end{array}$ & $\mathrm{kPa}$ & -0.02 \\
\hline Large_VPD threshold & Upper limit of mean hourly VPD required for conditions to be favorable for the ICY & $\mathrm{kPa}$ & -0.12 \\
\hline $\mathrm{RF}^{\mathrm{z}}$ & Reduction in DS after fungicide has been applied & $\%$ & 90 \\
\hline
\end{tabular}
significance level $P=0.05$ at each week.

TABLE 2. List of parameters and values used in POMICS for simulating severity of powdery mildew on cucurbits

${ }^{\mathrm{z}}$ Reduction factor. 
level (95\%). The CCC-based statistic was the $\rho C$ (Lin 1989). The purpose of this analysis was to estimate the level of variability in the observed data that could be explained by the model's simulation. This was performed across all data points observed in an experiment with the corresponding prediction from the model. The deviationbased statistics used mean squared deviation (MSD) (equations 5 to 8$)$.

$$
\begin{gathered}
\mathrm{MSD}=\mathrm{SD}+\mathrm{SDSD}+\mathrm{LCS} \\
\mathrm{SB}=\left(\frac{1}{n} \sum_{i=1}^{n}\left(x_{i}-y_{i}\right)\right)^{2} \\
\mathrm{SDSD}=\left(\sqrt{\frac{1}{n}} \sum_{i=1}^{n}\left(x_{i}-\bar{x}\right)-\sqrt{\frac{1}{n}} \sum_{i=1}^{n}\left(y_{i}-\bar{y}\right)\right)^{2} \\
\mathrm{LCS}=2\left(\sqrt{\frac{1}{n}} \sum_{i=1}^{n} x_{i}-\bar{x}\right)\left(\sqrt{\frac{1}{n}} \sum_{i=1}^{n}\left(y_{i}-\bar{y}\right)(1-r)\right)
\end{gathered}
$$

In equations 5 to $8, x$ is the model output; $y$ is the measurement; $x_{\mathrm{i}}$ and $y_{\mathrm{i}}$ are the simulated and measured values, respectively, for the $i$ th measurement from $n$ number of measurements; $\bar{x}$ and $\bar{y}$ are the means of $x_{i}$ and $y_{i}(i=1,2 \ldots n)$; and $r$ is the correlation coefficient between the simulation and measurement. The purpose of this analysis was to identify what caused the discrepancy, small or large, between observation and prediction. MSD (equation 5) has three additive components: (i) squared bias (SB), (ii) squared difference between predicted and observed standard deviations (SDSD), and (iii) lack of positive correlation weighted by the standard deviations of prediction and observation (LCS). MSD measures the total deviation between predictions and observations. The lower the value of MSD, the closer the prediction is to the observation. SB (equation 6) indicates the mean agreement between the model and observation, whereas SDSD (equation 7) and LCS (equation 8 ) together show how closely the model predicts variability around the mean. There are two sources of this variability: SDSD describes the magnitude of fluctuation among the $n$ observations and LCS describes the pattern of the fluctuation across $n$ observations.

\section{RESULTS}

Dynamics of progression through the ICY. The progress through ICY as simulated by the POMICS model is shown in Figure 2. This example is the simulation of the Gatton field study during the autumn 2011 (field trial 2) for the first complete ICY (ICY-1) and the beginning of the second cycle (ICY-2). The progression of ICY-1 is initiated by the GER process. The simulation graph shows that there was no progression of ICY-1 in the initial hours of the model because the unfavorable temperature and VPD for GER (Fig. 2, arrow 1). The process of GER commenced at $30 \mathrm{~h}$, when VPD and temperature were favorable for the process. After initiation of the GER process, the model simulated the progression of the LP until $21 \mathrm{~h}$, before the progression was delayed at 51 to $56 \mathrm{~h}$ due to the temperature dropping below the threshold of $10^{\circ} \mathrm{C}$ (arrow 2). The model then simulated the continued progression of LP until it was delayed again by low temperature at 75 to $80 \mathrm{~h}$ (arrow 3), 101 to $104 \mathrm{~h}$ (arrow 4), and 170 to $176 \mathrm{~h}$ (arrow 5). With such "delay and proceed" events, LP required more than $168 \mathrm{~h}$ to complete ICY-1 (arrow 6). ICY-1 was completed in 221 instead of $168 \mathrm{~h}$. The beginning of ICY-2 was also delayed by $26 \mathrm{~h}$ due to unfavorable conditions of temperature and VPD (arrow 7).

Model calibration. Using the calibrated parameters, the simulated progression of DS is shown in Figure 3 along with the DS observed in the field at Gatton (field trial 2). The calibrated model illustrates the progress of DS of powdery mildew in zucchini well. Quantitatively, the DS simulated by the model was within the 95\% confidence limit of the observations for all except one data point (28 March) (Fig. 3). The mean difference between the simulated DS level and the observed DS level was extremely low at only 0.04 for DS scales of 0 to 5 . The model also closely predicted the magnitude of fluctuation (standard deviation $=1.24$ ) among six

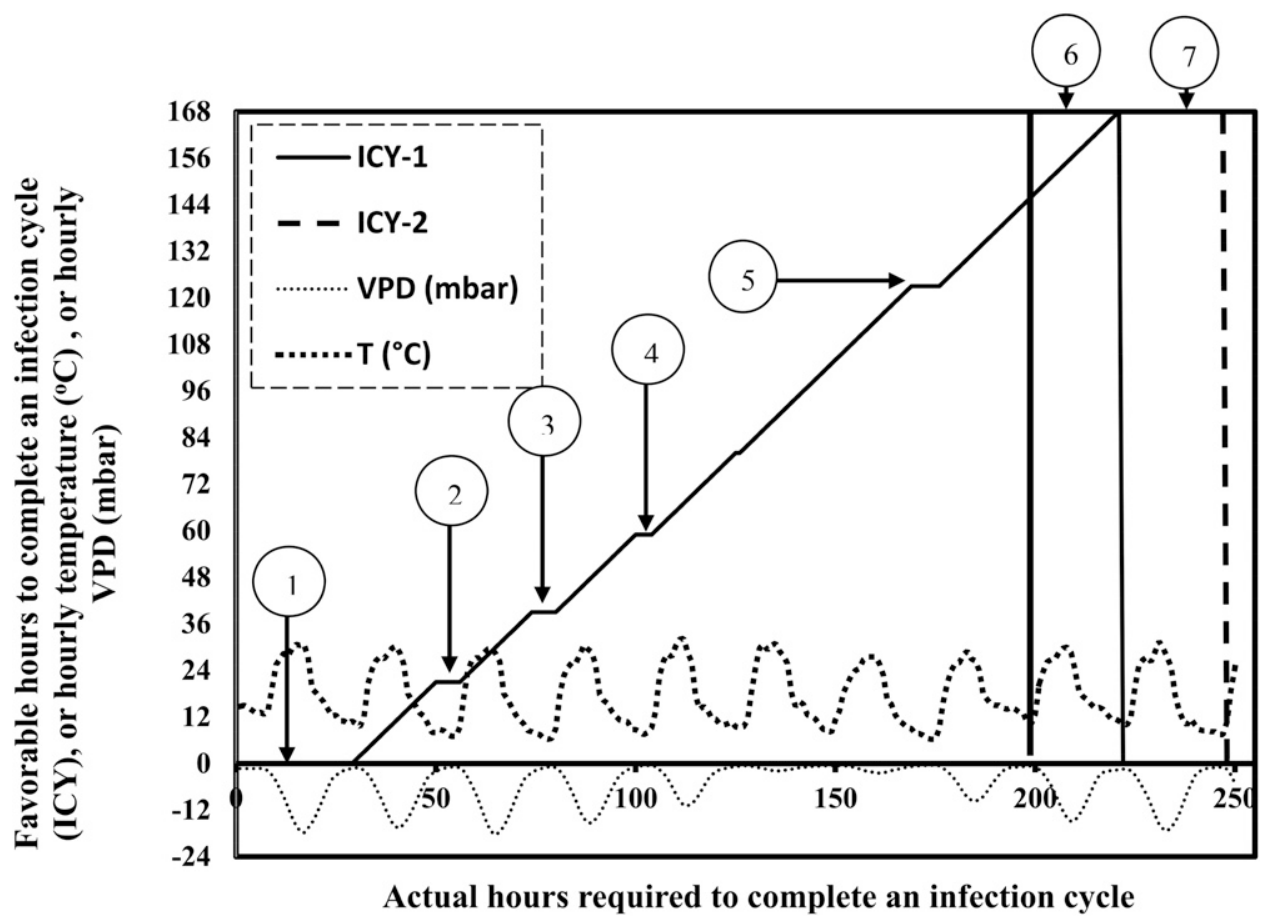

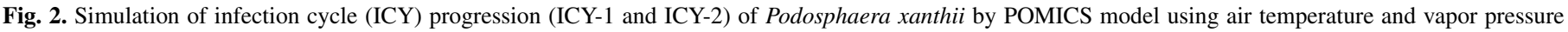

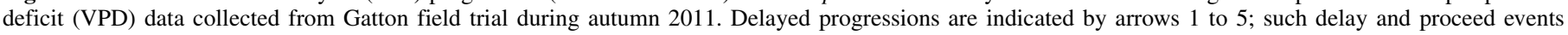

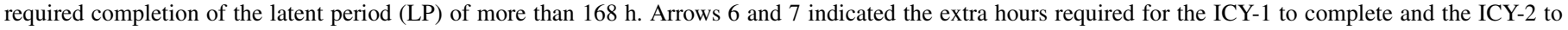
commerce. 
observations (standard deviation $=1.10$ ). In addition, the relationship between observation and simulation was strong at $\rho_{\mathrm{C}}=0.98$, $n=6$. This was reflected in the MSD analysis, which showed that the bias (SB) was zero and that SDSD and LCS were small but similar (Fig. 4A). A small SDSD of 0.02 indicated that the calibrated model largely simulated the magnitude of fluctuation between six observations. Similarly, a small LCS indicated that the model adequately predicted the pattern of the fluctuation between the observations.

Model validation. The first validation with the DS data of the Bowen field study (field trial 1) showed that the model simulated the observed data well (Fig. 5). Quantitatively, the model's simulation of the DS was within the $95 \%$ confidence limit for all observations. The relationship between simulation and observation was strong at $\rho_{\mathrm{C}}=0.99, n=4$. The mean difference between the simulated DS scale and the observed DS scale was small, at only 0.02 for DS level 0 to 5 . The model also closely predicted the magnitude of fluctuation ( standard deviation $=0.85$ ) among the four observations (standard deviation $=0.84)$. The root MSD (RMSD) between the calibrated model's simulation and the observation was reasonably low at 0.14 . The MSD analysis showed that the deviation of the model's simulation from the observation was attributed to a small
LCS and SB and zero SDSD (Fig. 4B). Zero SDSD indicates that the model largely simulated the magnitude of fluctuation between the four observations. A small SB indicates that the difference between the mean values of the simulation and the observation is small. A small LCS indicates that the model adequately simulated the pattern of fluctuation across the four data points.

The second validation of the POMICS model was performed with the DS data obtained from the CON treatment of the Gatton field study during spring 2011 (field trial 3). This validation showed that the model was able to simulate the observed data well (Fig. 6). Quantitatively, except for two data points for 8 and 15 November, the simulation of DS was within the $95 \%$ confidence limit of the DS observations. The mean difference between the simulated DS scale and the observed DS scale was very small (0.06) for DS levels 0 to 5. This small difference indicated that the relationship between the simulation and the observation was strongly correlated $\left(\rho_{C}=0.95\right.$, $n=8$ ). The model's simulation overestimated three data points at 8 and 15 November and 6 December. However, the difference between the simulations and the observations at these two points was small, at less than 0.5 . This small deviation was reflected in the MSD analysis that showed that the SB and SDSD were small but the LCS was larger than that in other simulations (Fig. 4C). A large LCS

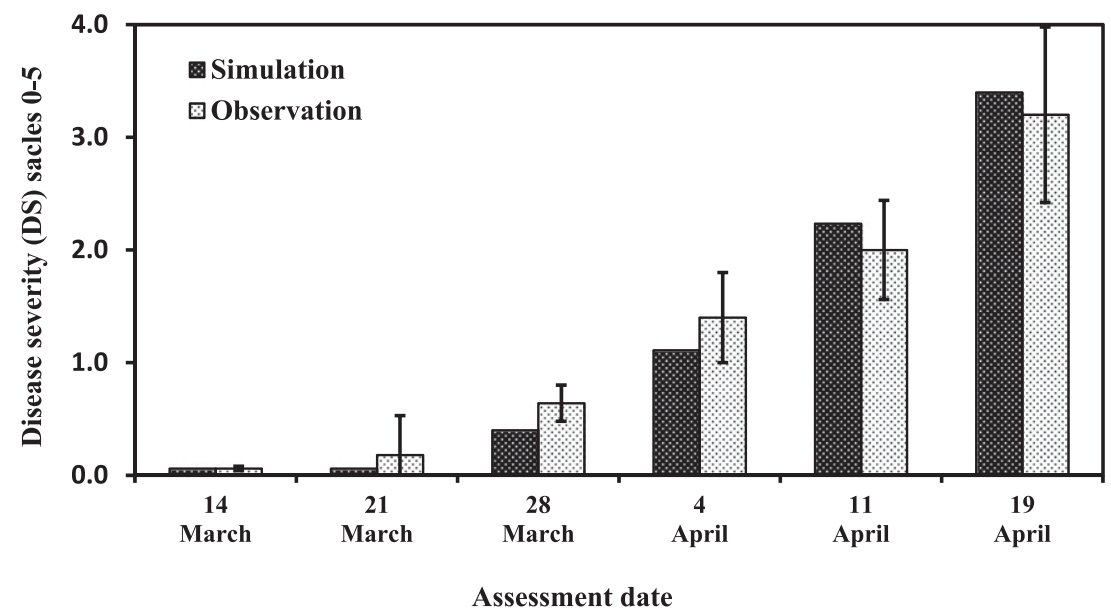

Fig. 3. Comparison between the model's simulation and the observation of disease severity (DS) of powdery mildew of zucchini as a part of calibration of the POMICS model. Observation data were collected from the Gatton field trial during autumn 2011. Observed DS data from the unsprayed treatment were used in the calibration. Each observed value is a mean of seven replicates, and confidence intervals of DS at $95 \%$ are indicated by error bars.

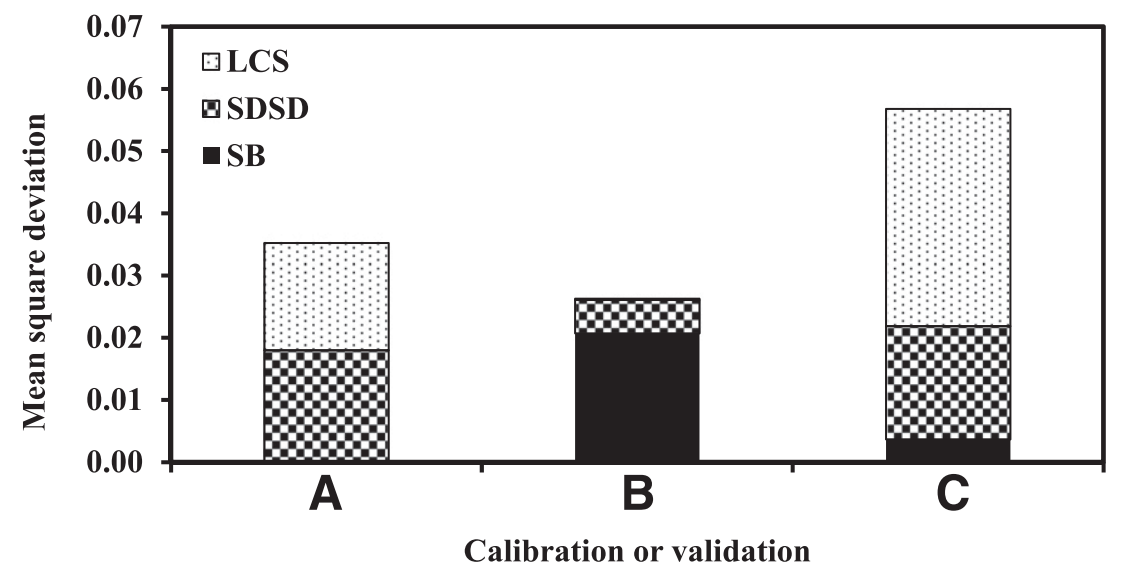

Fig. 4. Mean squared deviation and its components—squared bias (SB), squared difference between standard deviation (SDSD), and lack of correlation weighted by the standard deviations (LCS) — comparing the simulated and observed disease severity (DS) of powdery mildew in zucchini. Observed data were collected at two locations and in two seasons. A, Observed DS data from the Gatton field trial during autumn 2011; the data from the unsprayed treatment (CON) were used to calibrate the model. B, Observed DS from the Bowen field trial during spring 2008 were used to validate the model. C, Observed DS data from the Gatton field trial during spring 2011; the data collected from the CON were used to further validate the model. 
was probably contributed by the model and did not adequately simulate the pattern of fluctuation for the data points on 8 and 15 November.

Model simulation. Simulation with three versus four applications of fungicide. DS data used in this model simulation were from the Gatton field trial during autumn 2011. The POMICS model performed well in simulating the observed DS data from the INS treatment with four applications (Fig. 7). At the end of the growing season, the mean observed DS scale was recorded as 0.14 , with a $95 \%$ confidence limit of 0.78 , which was similar to the value simulated by the model ( 0.12 DS scale). The RMSD between the model's simulation and the observation was low, at only 0.08 . This small deviation in the model's simulation from the observation was attributed to the LCS (Fig. 8A). The model also performed very well in simulating the observed DS data from the INS treatment with three applications of fungicide (Fig. 7). At the end of the growing season, the observed DS scale recorded in the field was 0.16 and the model-simulated DS scale was 0.12 . This result suggests that the relationship between the simulation and the observation is well correlated, with a mean difference of only 0.02 for a DS scale of 0 to 5. This small deviation between the model's simulated DS scale and the observed DS scale was attributed to the lack of positive correlation weighted by the standard deviations
(Fig. 8B). There was no significant difference between the models that simulated a DS scale with four applications of fungicide and those that simulated a DS scale with three applications. This result suggests that the fourth application did not have any effect on the final status of the DS.

Simulation with two versus three applications of fungicide. The model simulated the observed data from the Gatton field trial during spring 2011 from a POMICS treatment (Fig. 9). At the end of the growing season, the DS scale recorded from the treatment was 0.54 , with a $95 \%$ confidence limit of 0.24 , which was closely simulated by the model (0.42). The RMSD between the model's simulation and observation was 0.17 . This deviation between the model's simulated DS value and the observed DS values was predominantly attributed to bias of means (SB), a small SDSD, and zero LCS (Fig. 8D). Zero LCS indicates that the model with the RF of 0.10 was adequate to simulate the pattern of fluctuation between the observed data and simulated data. The large SB was explained by the difference between the mean simulation and observation values at two data points for 8 and 15 November. At these two points, the model overestimated DS but the mean difference between the simulated and observed values for both points was less than 0.5 (Fig. 9). The difference between the mean of the DS scale with two applications of fungicide applied as

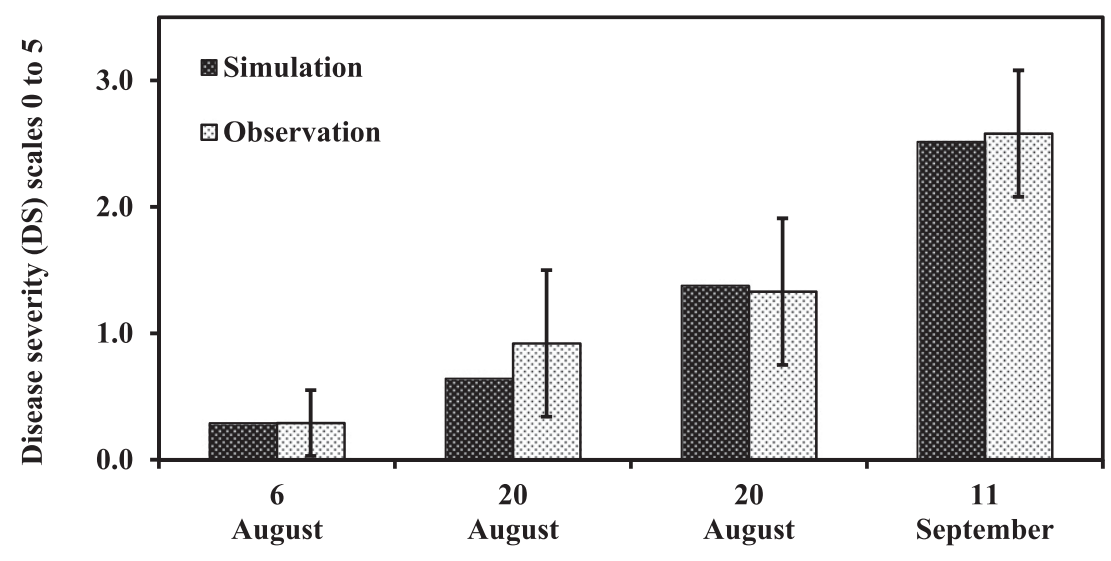

Assessment date

Fig. 5. Comparison of the model's simulation and the observation of disease severity (DS) of powdery mildew in zucchini. Observed data were collected from the Bowen field trial during spring 2008 (field trial 1). Each observed value is a mean of five replicates, and confidence intervals of DS at $95 \%$ are indicated by error bars.

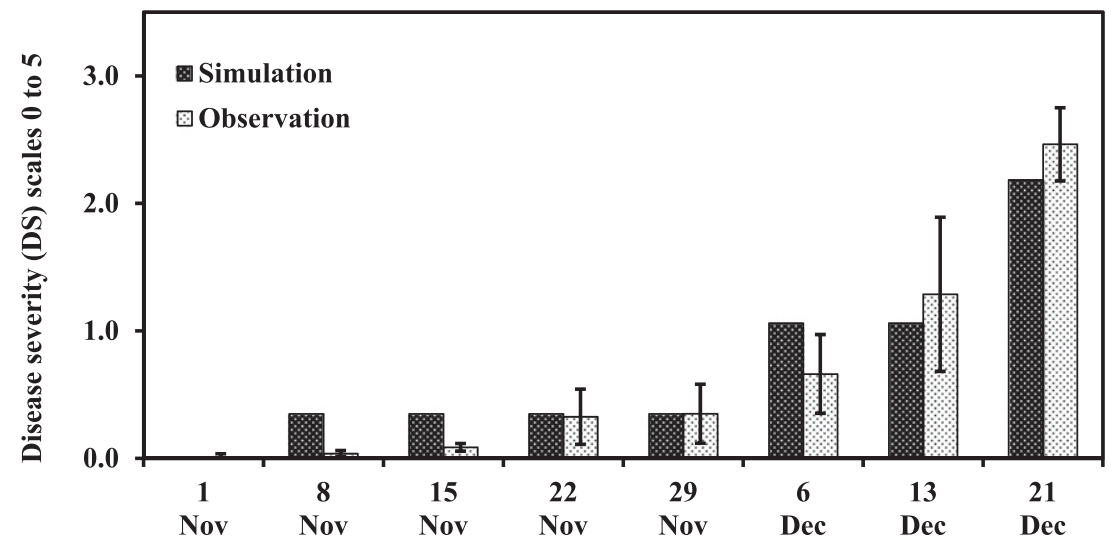

Assessment date

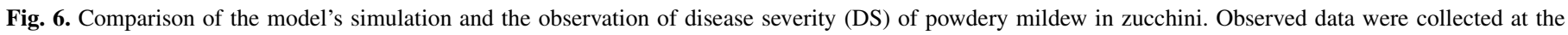

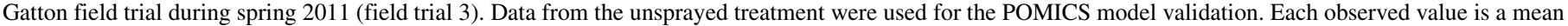
of five replicates, and confidence intervals of DS at $95 \%$ are indicated by error bars. 
guided by the POMICS and the mean of the DS scale with three applications of fungicide applied as guided by the industry standard practice was low $(<0.5)$. This result indicates that the improved practice by the POMICS is able to reduce at least one fungicide application during a growing season.

\section{DISCUSSION}

On the basis of a disease epidemic model, this study explored the feasibility of curtailing one or more fungicide applications in the commercial production of zucchini in Queensland, Australia. The industry considers that the intensive use of fungicides is required to successfully manage powdery mildew in this crop; thus, there is much room for improvement.

Because epidemics of powdery mildew, as for other crop diseases, are driven by weather conditions, a simple weather-based model was developed to meet the objective of the study. The model simulates the increase in powdery mildew of a zucchini crop as secondary ICY. The POMICS model is based on the principle of "favorable conditions" for the development of the pathogen to generate a number of ICY in a single growing season. It may be noted that, with a 7-day ICY, as many as seven such cycles have been recorded in zucchini crops in Queensland over a 50-day growing season (McGrath and Thomas 1996).

The principle of favorable conditions for progression toward an ICY has been widely applied in modeling other crop diseases. Examples include simulating the maturity of ascospores of ascochyta blight (Didymella rabiei) in chickpea (Cicer arietinum) (Shtienberg et al. 2005), blackleg disease (Leptosphaeria maculans; L. biglobosa) in canola (Brassica napus) (Salam et al. 2003, 2007), and ascochyta or blackspot (D. pinodes) in field pea (Pisum sativum) (Salam et al. 2011). Five weatherrelated parameters of the model (ICY complete, low_ $\mathrm{T}_{\text {threshold, }}$, high_ $\mathrm{T}_{\text {threshold }}$, small_VPD threshold $_{\text {, }}$, and large_VPD threshold) were either measured or derived by calibration with the field experimental data. The values of these parameters largely fell within the ranges that were cited in the literature (MacManus and Akem 2008; McGrath and Thomas 1996; Reuveni and Rotem 1974; Yarwood 1957). In addition to temperature and VPD, rainfall and free water also have an impact on powdery mildew growth, as discussed by Sivapalan (1993) and Jarvis et al. (2002). Raindrops $4 \mathrm{~mm}$ in diameter released from a height of $2.5 \mathrm{~m}$ onto infected leaves can reduce the number of powdery mildew conidia remaining. However, free water has a detrimental effect only on ungerminated conidia and has minimal effect on overall

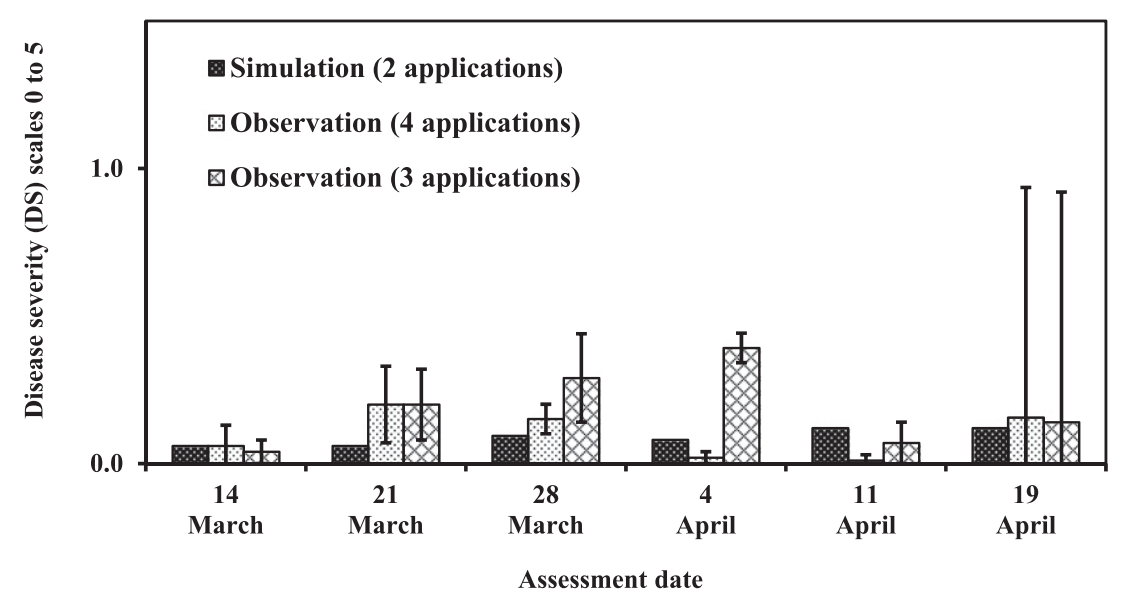

Fig. 7. Comparison of the model's simulation and observation of disease severity (DS) in zucchini. Observed DS datasets were from two treatments (field trial 3): (i) industry standard practice (four applications) and (ii) POMICS (three applications). Each observed value is a mean of seven replicates, and confidence intervals of DS at $95 \%$ are indicated by error bars.

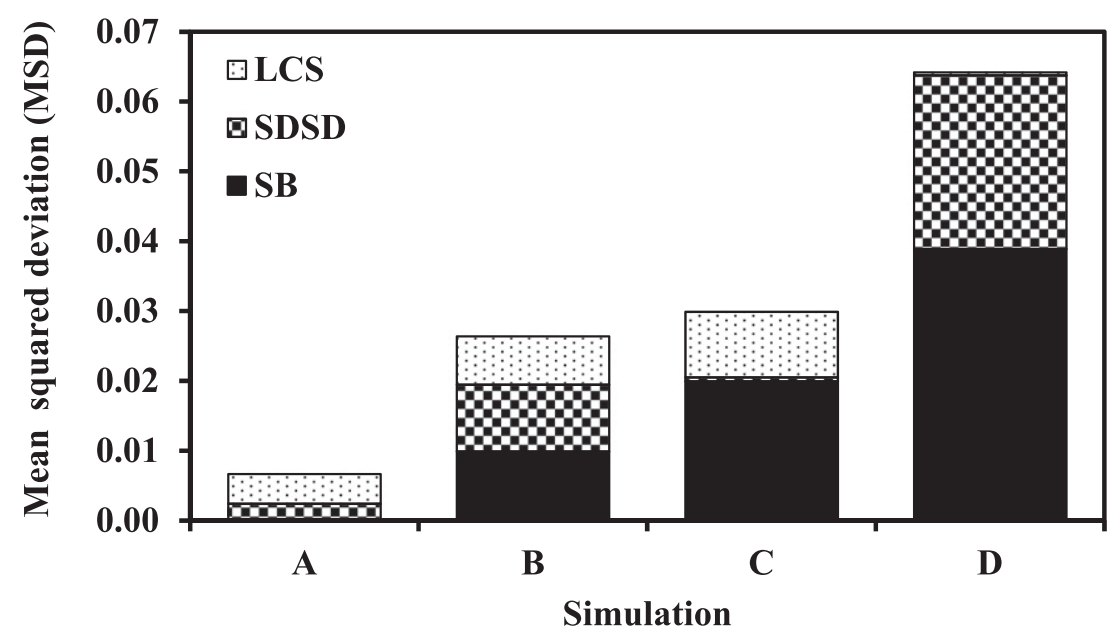

Fig. 8. Mean squared deviation and its components—squared bias (SB), squared difference between standard deviation (SDSD), and lack of correlation weighted by the standard deviations (LCS) — comparing simulated and observed disease severity (DS) of powdery mildew in zucchini collected at Gatton from two field trials. Field trial conducted during autumn: observed DS data from A, the industry standard practice (INS) treatment with four applications of fungicide and $\mathbf{B}$, the treatment with three applications, according to the risk assessment index developed by Gubler et al. (1999). Field trial conducted during spring 2011: observed DS data from $\mathbf{C}$, the INS treatment with three applications and $\mathbf{D}$, the treatment with two applications, according to the POMICS model. 


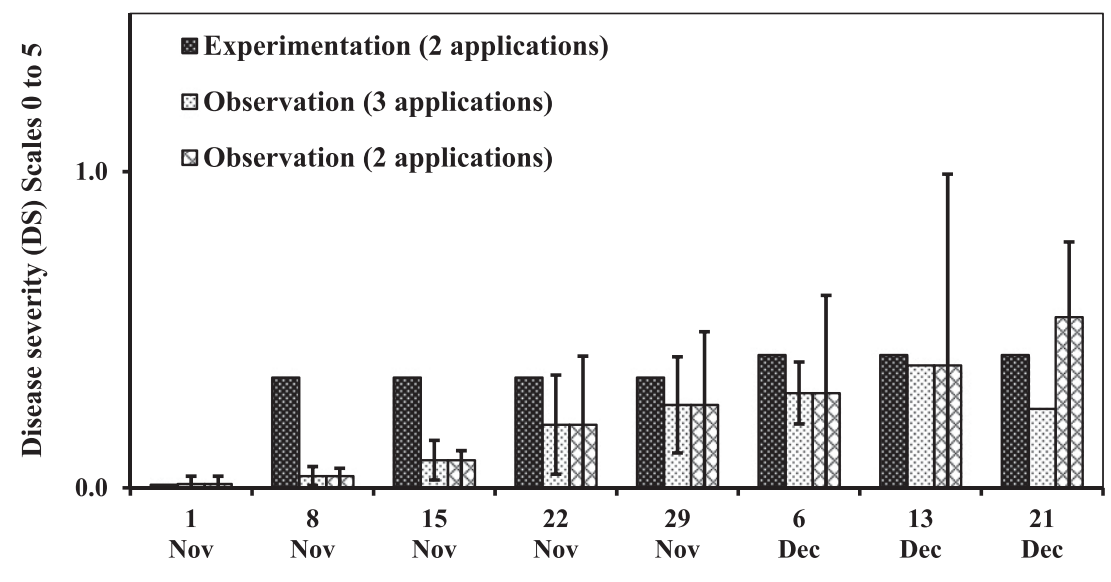

Assessment date

Fig. 9. Comparison of the model's simulation and observations of disease severity (DS) of powdery mildew in zucchini. Observed data were collected from Gatton during spring 2011. Datasets were obtained from two treatments: (i) three applications of fungicide applied according to the industry standard practice and (ii) two applications of fungicide applied according to the POMICS model. Each observed value is a mean of five replicates, and confidence intervals of DS at $95 \%$ are indicated by error bars.

colonization and sporulation of powdery mildew. Additionally, rainfall is rare during the growing season in the area for which the model was developed.

In our study, the relationship between the cycle of infection and DS, the other part of the model, was based on the logistic growth of a typical polycyclic disease such as powdery mildew in cucurbits. The logistic function of disease development has been used in many studies (Correll et al. 1988; Jeger 2004; Lalancette and Hickey 1986; Rossi and Giosué 2003). Because of the model's calibration using natural disease development in the field without any application of fungicides, it was encouraging to have a small RMSD (0.2). The POMICS model validation was performed with two datasets of field data where the disease developed naturally. When validated with an independent dataset collected at Bowen from a treatment without fungicide application, the model agreed well with the field observation (RMSD of DS level $=0.14$ ). It may be noted that the model was not calibrated in this environment. In a second validation with a dataset from Gatton during the spring season in 2011, the POMICS model was able to explain $97 \%$ of the variability in the observed data. The model was calibrated with the data from this environment; however this was done for autumn season conditions. These results of validation imply that the model is significantly robust to simulate the severity of powdery mildew in zucchini between growing seasons and between growing environments.

POMICS performed well in simulating all five of the datasets collected from two field studies at Gatton. These datasets included between two and four fungicide applications. During the testing, POMICS was able to simulate high- and low-risk disease status. Furthermore, the model's prediction of DS was responsive to the number of fungicide applications. Such responsiveness indicates that the model has the potential to be used as a tool to guide the scheduling of judicious fungicide applications. However, there were some discrepancies observed between simulation and observed data, notably in predicting a part of the Gatton field trial (field trial 3 of spring 2011) (Fig. 6). In this comparison, although the simulation and observation were in good agreement from 22 November on, differences existed in predicting the disease in the early period ( 8 and 15 November). POMICS simulated a higher level of the disease on 8 November which remained unchanged in the following week (15 November). In contrast, field data showed low disease on 8 November which increased in the following week; however, the difference in observed DS between 8 and 15 November was not significant. When we revisited experimental data, we found that two replicates of 8 November and one replicate of 15 November observation did not produce any disease. We suspect microenvironment differences between the fields in the experiment. Unfortunately, no microclimate data were available to run the model to further scrutinize the model's simulation at those points of discrepancies. However, we note that more testing of the model using diverse disease scenarios would suggest the reasons behind such discrepancies and advocate fine tuning parameter values of the model if warranted.

The model proved (Fig. 9) that two applications of fungicides was as good as three applications in terms of managing DS in zucchini. However, the use of POMICS to control powdery mildew needs to be reassessed in future studies for high DS. In this study, the model was tested on two different zucchini cultivars, Amanda (Gatton field studies) and Congo (Bowen field study). The applicability of the model also needs to be extended to other cucurbit hosts in the future. At this stage, it is evident that the model may be applied to simulate powdery mildew in other cucurbit species, as based on research findings by del Pino et al. (2002) of no significant difference between Podosphaera xanthii development on cucurbits such as cucumber, melon, zucchini, and watermelon. Potentially, however, the model with proper calibration or validation may also be applied to simulate the DS of powdery mildew in a wider range of cucurbit hosts.

In this study, the model appropriately simulated the DS of powdery mildew in zucchini. This performance was primarily achieved for the environment that yielded the data used to calibrate, test, and perform simulation with the model. For its confident application in other environments, it is advisable to perform multiseason and locationspecific testing. In modeling, reality is simplified, partly because our understanding of basic processes is limited and partly because this enables us to handle the model (Salam 1992). Testing would help to refine the model for the purpose for which it is designed.

\section{ACKNOWLEDGMENTS}

We thank H. Robertson, R. Bourne, B. Jahnke, A. Lisle, J. Duff, D. Schofield, M. Firrell, and S. Soderquist for technical help. This project was funded by Horticulture Australia Limited and the Malaysia Ministry of High Education for a Ph.D. scholarship.

\section{LITERATURE CITED}

Arafat, K. H. 2015. Application of statistical model for forecasting powdery mildew of grapes under Egyptian conditions based on meteorological data. Int. J. Plant Pathol. 6:48-57.

Ben-Naim, Y., and Cohen, Y. 2015. Inheritance of resistance to powdery mildew race $1 \mathrm{~W}$ in watermelon. J. Phytopathol. 105:1446-1457. 
Caffi, T., Legler, S. E., Rossi, V., and Bugiani, R. 2012. Evaluation of a warning system for early-season control of grapevine powdery mildew. Plant Dis. 96:104-110.

Cao, X., Yao, D., Xu, X., Zhou, Y., Ding, K., Duan, X., Fan, J., and Luo, Y. 2015. Development of weather-and airborne inoculum-based models to describe disease severity of wheat powdery mildew. Plant Dis. 99:395-400.

Cheatham, M. R., Rouse, M. N., Esker, P. D., Ignacio, S., Pradel, W., Raymundo, R., Sparks, A. H., Forbes, G. A., Gordon, T. R., and Garrett, K. A. 2009. Beyond yield: Plant disease in the context of ecosystem services. J. Phytopathol. 99:1228-1236.

Correll, J. C., Gordon, T. R., and Elliott, V. J. 1988. Powdery mildew on tomato: The effect of planting date and triadimefon on disease onset, progress, incidence, and severity. J. Phytopathol. 78:512-519.

Cunnington, J. H., Lawrie, A. C., and Pascoe, I. G. 2004. Molecular determination of anamorphic powdery mildew fungi on the Fabaceae in Australia. Aust. Plant Pathol. 33:281-284.

Dal Santo, P., and Holding, R. 2009. Best Practice for Vegetable: Introductory Document. Online publication. http://www.soilwealth.com.au/imagesDB/ news/7.TL176.pdf

de Vallavieille-Pope, C., Giosue, S., Munk, L., Newton, A. C., Niks, R. E., Ostergard, H., Pons-Kuhnemann, J., Rossi, V., and Sache, I. 2000. Assessment of epidemiological parameters and their use in epidemiological and forecasting models of cereal airborne diseases. J. Agron. 20:715-727.

del Pino, D., Olalla, L., Pérez-Garcéa, A., Rivera, M. E., García, S., Moreno, R., de Vicente, A., and Torés, J. A. 2002. Occurrence of races and pathotypes of cucurbit powdery mildew in South Eastern Spain. Phytoparasitica 30:459-466.

Gubler, W. D., Rademacher, M., Vasquez, S. J., and Thomas, C. S. 1999. Control of powdery mildew using the UC Davis Powdery Mildew Risk Index. Online publication. The American Phytopathology Society, St Paul, MN. http://www. apsnet.org/publications/apsnetfeatures/Pages/UCDavisRisk.aspx

Jarvis, W. R., Gubler, W. D., and Grove, G. G. 2002. Epidemiology of powdery mildews in agriculture pathosystems. In: The Powdery Mildews. A Comprehensive Treatise. R. R. Bélanger, W. R. Bushnell, A. J. Dik, and T. L. W. Carver, eds. American Phytopathological Society, St. Paul, MN.

Jeger, M. J. 2004. Analysis of disease progress as a basis for evaluating disease management practices. Annu. Rev. Phytopathol. 42:61-82.

Keinath, A. P. 2015. Efficacy of fungicides against powdery mildew on watermelon caused by Podosphaera xanthii. Crop Prot. 75:70-76.

Lalancette, N., and Hickey, K. D. 1986. Disease progression as a function of plant growth. J. Phytopathol. 76:1171-1175.

Lin, L. I.-K. 1989. A concordance correlation coefficient to evaluate reproducibility. Biometrics 45:255-268.

MacManus, G. P. V., and Akem, C. 2008. Epidemiological studies of powdery mildew on zucchini (cv. Congo, SPS) in 2008. Vegetable Pathology Workshop. The Department of Employment, Economic Development and Innovation, Queensland, Australia.

Madden, L. V., Hughes, G., and van den Bosch, F. 2007. Introduction to modeling in epidemiology. In: The Study of Plant Disease Epidemics. American Phytopathological Society, St. Paul, MN.

McGrath, M. T. 1994. Heterothalism in Sphaerotheca fuliginea. Mycologia 86:517-523.

McGrath, M. T. 2001. Fungicide resistance in cucurbit powdery mildew: Experiences and challenges. Plant Dis. 85:236-245.

McGrath, M. T., and Staniszewska, H. 1996. Management of powdery mildew in summer squash with host resistance, disease threshold-based fungicide program, or an integrated program. Plant Dis. 80:1044-1051.

McGrath, M. T., and Thomas, C. E. 1996. Powdery mildew. Pages 28-30 in: Compendium of Cucurbit Diseases. T. A. Zitter, D. L. Hopkins, and C. E. Thomas, eds. American Phytopathological Society, St. Paul, MN.
Moyer, M. M., Gadoury, D. M., Wilcox, W. F., and Seem, R. C. 2016. Weather during critical epidemiological periods and subsequent severity of powdery mildew on grape berries. Plant Dis. 100:116-124.

Napier, T. 2009. Pumpkin production. Primefact 964. Online publication. New South Wales Government. http://www.dpi.nsw.gov.au/_data/assets/pdf_file/ 0004/311485/Pumpkin-production.pdf

O’Brien, R. G., Vawdrey, L. L., and Glass, R. J. 1988. Fungicide resistance in cucurbit powdery mildew (Sphaerotheca fuliginea) and its effect on field control. Animal Prod. Sci. 28:417-423.

Pérez-García, A., Romero, D., Fernandez-Ortuño, D., López-Ruiz, F., De Vicente, A., and Torés, J. A. 2009. The powdery mildew fungus Podosphaera fusca (synonym Podosphaera xanthii), a constant threat to cucurbits. Mol. Plant Pathol. 10:153-160.

Reuveni, R., and Rotem, J. 1974. Effect of humidity on epidemiological patterns of the powdery mildew Sphaerotheca fuliginea on squash. Phytoparasitica 2:25-33.

Rossi, V., and Giosué, S. 2003. A dynamic simulation model for powdery mildew epidemics on winter wheat. Bull. OEPP 33:389-396.

Salam, M. U. 1992. A system approach to the study of potential of Boro rice in the Hoar region of Bangladesh. Ph.D. thesis, University of Reading, United Kingdom.

Salam, M. U., Davidson, J. A., Thomas, G. J., Ford, R., Jones, R. A., Lindbeck, K. D., MacLeod, J. W., Kimber, J. B., Galloway, J., Mantri, N., van Leur, J. A. G., Coutts, B. A., Freeman, A. J., Richardson, H., Aftab, M., Moore, K. J., Knights, E. J., Nash, P., and Verrell, A. 2011. Advances in winter pulse pathology research in Australia. Aust. Plant Pathol. 40: 549-567

Salam, M. U., Fitt, B. D. L., Aubertot, J. N., Diggle, A. J., Huang, Y. J., Barbetti, M. J., Gladders, P., Jedryczka, M., Khangura, R., Wratten, N., Fernando, W., Penaud, A., Pinochet, X., and Sivasithamparam, K. 2007. Two weather-based models for predicting onset of seasonal release of ascospores of Leptosphaeria maculans or L. biglobosa, causes of Phoma stem canker of oilseed rape. J. Plant Pathol. 56:412-423.

Salam, M. U., Khangura, R. K., Diggle, A. J., and Barbetti, M. J. 2003. Blackleg Sporacle: A model for predicting onset of pseudothecia maturity and seasonal ascospore showers in relation to blackeg of canola. J. Phytopathol. 93:1073-1081.

Sapak, Z. 2012. Development of a disease model for powdery mildew of cucurbits. Ph.D. thesis, The University of Queensland, Australia.

Shtienberg, D., Gamliel-Atinsky, E., Retig, B. S., Brener, A., and Dincor, A. 2005. Significance of preventing primary infection by Didymella rabiei and development of a model to estimate the maturity of pseudothecia. Plant Dis. 89:1027-1034

Sivapalan, A. 1993. Effects of impacting rain drops on the growth and development of powdery mildew fungi. Plant Pathol. 42:256-263.

Vanderplank, J. E. 1982. Host-Pathogen Interactions in Plant Disease. Academic Press, New York.

van Maanen, A., and Xu, X. M. 2003. Modelling plant disease epidemics. Eur. Plant Pathol. 109:669-682.

Willmott, C. J., Ackleson, S. G., Davis, R. E., Feddema, J. J., Klink, K. M., Legates, D. R., O'Donnell, J., and Rowe, C. M. 1985. Statistics for the evaluation and comparison of models. Geophys. Res. 90: 8995-9005.

$\mathrm{Xu}$, X. M. 1999. Modelling and forecasting epidemics of apple powdery mildew (Podosphaera leucotricha). J. Plant Pathol. 48:462-471.

Yarwood, C. E. 1957. Powdery mildews. Bot. Rev. 23:235-301.

Zadoks, J. C. 1972. Methodology of epidemiological research. Annu. Rev. Phytopathol. 10:253-276. 